\title{
Qualidade fisiológica de sementes armazenadas de Amburana cearensis (Allemão) A.C. Smith
}

\section{Physiological quality of Amburana cearensis (Allemão) A.C. Smith seeds stored}

\author{
Roberta Sales Guedes ${ }^{*}$; Edna Ursulino Alves ${ }^{2}$; Edilma Pereira Gonçalves ${ }^{3}$; \\ Jeandson Silva Viana ${ }^{3}$; Pablo Radamés Cabral de França ${ }^{4}$; Sueli da Silva Santos ${ }^{5}$
}

\begin{abstract}
Resumo
O objetivo deste trabalho foi determinar as melhores condições e períodos de armazenamento para conservação da viabilidade e vigor das sementes de Amburana cearensis (Allemão) A.C. Smith. O experimento foi instalado no Laboratório de Análise de Sementes (CCA - UFPB), seguindo-se um delineamento inteiramente ao acaso, cujos tratamentos constituíram-se de sementes acondicionadas em três tipos de embalagens (saco de papel Kraft, saco de pano de algodão e embalagem de papel alumínio); armazenadas em dois ambientes: ambiente de laboratório $\pm 25^{\circ} \mathrm{C}$ e $74,5 \%$ UR e geladeira $6 \pm 2{ }^{\circ} \mathrm{C}$ e $38 \%$ \pm 3 UR), durante 270 dias. As características avaliadas foram: teor de água, porcentagem e índice de velocidade de emergência, comprimento e massa seca de plântulas. Após 270 dias de armazenamento a emergência das plântulas de $A$. cearensis acondicionadas na embalagem de papel alumínio e armazenadas em laboratório foi de $68 \%$. A emergência e o vigor das sementes de $A$. cearensis são conservados, com eficiência, em todos os ambientes e embalagens por 90 dias e no ambiente de laboratório na embalagem de alumínio por 180 dias.

Palavras-chave: Cumaru, emergência, vigor, embalagens e ambientes
\end{abstract}

\begin{abstract}
This work aimed to determine the best conditions and storage periods adapted to conservation of seed vigor for Amburana cearensis (Allemão) A.C. Smith. The experiment was conducted at the Laboratory of Analysis of Seeds (CCA/UFPB), using an entirely randomized design. The treatments consisted of $A$. cearensis seeds packaged in: paper Kraft bags, bags of cotton and foil aluminum, two storage conditions: room temperature and humidity conditions and refrigerator for 270 days. The evaluated characteristics were: moisture content, percentage of emergence and emergence speed index (ESI), seedling length, and seedling dry matter. After 270 days of storage the emergence of $A$. cearensis seedlings of conditioned in aluminum packing and stored at laboratory was of $68 \%$. The emergency and the vigor of $A$. cearensis seeds are conserved, with efficiency, in all the storage conditions and packings for 90 days; and under environmental conditions in packing of aluminum for 180 days.
\end{abstract}

Key words: Cumaru, emergence, vigor, packaging, storage conditions

${ }_{1}$ Bióloga, doutoranda em Agronomia, Depto. de Fitotecnia, CCA- UFPB -Universidade Federal de Paraíba; Cx. Postal. 02, Areia - PB, Cep: 58.397 - 000 Brasil. E-mail: roberta_biologa09@yahoo.com.br;

${ }^{2}$ Prof ${ }^{\mathrm{a}}$. Adjunta do Depto. de Fitotecnia, CCA/UFPB. E-mail: ednaursulino@cca.ufpb.br

3 Profes ${ }^{\text {es }}$ Adjuntos UFRPE -Universidade Federal Rural de Pernambuco, UAG, Garanhuns - PE. E-mail: edilmapg@hotmail.com; jeandsonsv@hotmail.com

${ }^{4}$ Eng. Agrônomo, mestrando em agronomia, Depto. de Fitotecnia, CCA-UFPB; Areia - PB. E-mail: pabloradames@hotmail. com

5 Aluna de graduação em Agronomia, Depto. de Fitotecnia, CCA-UFPB; Areia - PB. E-mail: suelidasilvasantos@yahoo.com.br

* Autor para correspondência 


\section{Introdução}

O cumarú (Amburana cearensis (Allemão) A.C. Smith) é uma Fabaceae popularmente conhecida por suas qualidades madeireiras e suas aplicações na medicina popular (LORENZI, 2002), sendo listada como espécie ameaçada de extinção (IBAMA, 2008).

A qualidade fisiológica das sementes tem sido um dos aspectos mais pesquisados nos últimos anos, em conseqüência de estarem sujeitas a diversas mudanças degenerativas, as quais podem ser de origem bioquímica, fisiológica e física que ocorrem após a sua maturidade, e que estão associadas à redução do vigor (ALIZAGA et al., 1990). Assim, o armazenamento é prática fundamental para manter a qualidade fisiológica da semente e garantir a manutenção de vigor e viabilidade no período entre a colheita e a semeadura (AZEVEDO et al., 2003).

A utilização de sementes de baixa qualidade é um dos fatores responsáveis pela obtenção de mudas de espécies florestais de menor qualidade, com reflexos negativos no estabelecimento e na uniformidade dos povoamentos devido ao fato da semeadura não ocorrer logo após a colheita, sendo necessário o armazenamento em local e condições que permitam sua conservação com o mínimo de deterioração (CORVELLO et al., 1999).

$\mathrm{Na}$ tecnologia de sementes florestais, o armazenamento assume papel fundamental para a preservação do seu poder germinativo, tendo em vista a dificuldade de conservação, época de dispersão e heterogeneidade de produção. A conservação da qualidade fisiológica da semente sob determinadas condições ambientais de temperatura e umidade relativa está relacionada ao tipo de embalagem empregada (KAGEYAMA et al., 1992).

A umidade relativa do ar e a temperatura do armazenamento influenciam diretamente a atividade respiratória das sementes, de forma que Delouche et al. (1973) recomendaram a conservação de sementes a temperatura de $20^{\circ} \mathrm{C}$, umidade relativa do ar de $50 \%$ e teor de água de no máximo $12 \%$ para sementes amiláceas e $8 \%$ para oleaginosas. Para um armazenamento por períodos prolongados é necessário um controle mais rigoroso da umidade e da temperatura, o que torna o processo mais oneroso, porém, mais eficiente (CARNEIRO; AGUIAR, 1993).

A rapidez de deterioração das sementes de algumas espécies nativas e o período em que a viabilidade pode ser mantida varia de algumas semanas a poucos meses, por isso as pesquisas sobre armazenamento de sementes de espécies florestais assumem caráter de extrema importância (CARNEIRO; AGUIAR, 1993). Deste modo, o principal objetivo do armazenamento de sementes é o de reduzir a velocidade de deterioração, visto que a melhoria da qualidade não é possível, mesmo em condições ideais (VILLELA; PEREZ, 2004).

Para Carvalho e Nakagawa (2000), o armazenamento das sementes pode ser influenciado por fatores como a qualidade fisiológica inicial, condições climáticas durante a maturação, grau de maturação no momento da colheita, teor de água, ataque de pragas, doenças e patógenos, grau de injúria mecânica, embalagem e características do ambiente (temperatura e umidade relativa do ar).

A câmara fria foi eficiente para armazenar sementes de Cedrela fissilis Vell. com teor de água de $10 \%$, acondicionadas em embalagem de vidro transparente e fechado hermeticamente por 12 meses. Entretanto, os autores verificaram que quando as sementes foram armazenadas em câmara seca sua conservação não foi possível nem por um período de seis meses (CORVELLO et al., 1999).

Estudos realizados com Tabebuia heterophylla (A.P. Candolle) Britton demonstraram que suas sementes quando não liofilizadas e armazenadas em câmara fria se conservaram melhor do que as liofilizadas e armazenadas nos ambientes não controlados e de câmara seca (SILVA et al., 2001). Sementes de Caesalpinia echinata Lam. quando armazenadas sob condições normais de ambiente $\left(22 \pm 7^{\circ} \mathrm{C}\right)$ perderam a viabilidade em menos de três 
meses. No entanto, sob baixa temperatura (câmara fria a $7 \pm 1^{\circ} \mathrm{C}$ ) foi possível manter a viabilidade das mesmas por até 18 meses, com germinação superior a $80 \%$ (BARBEDO; BILIA; FIGUEIREDO, 2002).

O ambiente de laboratório, sem controle de temperatura e umidade relativa do ar não foi eficiente para conservar a qualidade fisiológica das sementes de Acacia polyphylla DC. No entanto, a qualidade fisiológica foi mantida por dois anos, quando as sementes foram acondicionadas em embalagem impermeável e em câmara fria (ARAÚJO NETO et al., 2005). As sementes de Jacaranda cuspidifolia Mart. mantiveram-se conservadas por até 150 dias em ambiente de refrigeração $\left(12 \pm 2^{\circ} \mathrm{C}\right)$ e condições ambientais $\left(25 \pm 2{ }^{\circ} \mathrm{C}\right)$, com elevada qualidade fisiológica (SCALON et al., 2006). A conservação das sementes de Cupania vernalis Cambess. por um período de 240 dias, foi favorecida com a manutenção do teor de umidade em torno de $40 \%$, associado à temperatura de $10^{\circ} \mathrm{C}$ (VIEIRA et al., 2008).

Devido à inexistência de informações sobre o comportamento das sementes de Amburanacearensis no armazenamento, este trabalho foi conduzido com o objetivo de avaliar o efeito de diferentes embalagens e ambientes de armazenamento para manutenção da qualidade fisiológica das mesmas.

\section{Material e Métodos}

O experimento foi conduzido no Laboratório de Análise de Sementes (LAS), do Centro de Ciências Agrárias, da Universidade Federal da Paraíba (CCA - UFPB), em Areia - PB, com sementes de Amburana cearensis coletadas manualmente de 10 plantas matrizes no início do processo de deiscência dos frutos, no município de Patos - PB. Após colhidas as sementes foram beneficiadas por meio de debulha manual e mantidas em laboratório, à sombra, para secagem natural por cinco dias. Posteriormente foram homogeneizadas e acondicionadas em embalagens de saco de papel, saco de pano de algodão e embalagem de papel alumínio (sementes envolvidas em quatro partes de $20 \mathrm{~cm}^{2}$ do papel alumínio superpostas e em seguidas enroladas e pressionadas com as mãos, afim de não permitir entrada de ar), e armazenadas em ambiente de laboratório $\left( \pm 25^{\circ} \mathrm{C}\right.$ e $74,5 \%$ UR) e geladeira (6 $\pm 2{ }^{\circ} \mathrm{C}$ e $38 \% \pm 3$ UR), por um período de 270 dias. Inicialmente a cada 45 dias foram retiradas amostras de cada embalagem e ambiente de armazenamento para avaliação dos seguintes parâmetros:

Teor de água - $\mathrm{O}$ teor de água foi determinado, antes e a cada 45 dias de armazenamento utilizandose quatro subamostras de 10 sementes para cada tratamento, sendo colocadas em estufa a $105 \pm 3^{\circ} \mathrm{C}$, por 24 horas, seguindo as recomendações de Brasil (1992).

Teste de emergência - $O$ teste de emergência foi instalado em casa de crescimento, com quatro repetições de 25 sementes, semeadas em bandejas plásticas com dimensões de $0,40 \times 0,40 \times 0,11 \mathrm{~m}$, contendo areia lavada e esterelizada, sendo realizadas irrigações diárias para manutenção da umidade do substrato. As contagens foram feitas diariamente, do $12^{\circ}$ ao $25^{\circ}$ dia de teste, computando-se as plântulas que emitiram o epicótilo, e os resultados foram expressos em porcentagem.

Índice de velocidade de emergência (IVE) O índice de velocidade de emergência (IVE) foi determinado mediante contagem diária do número de plântulas emersas durante 25 dias e o índice determinado de acordo com a fórmula proposta por Maguire (1962); onde

$$
I V E=\frac{E_{1}+E_{2}+\ldots+E_{n}}{N_{1}+N_{2}+\ldots+N_{n}},
$$

em que IVE = índice velocidade de emergência; $\mathrm{E}_{1}$, $\mathrm{E}_{2}, \ldots \mathrm{E}_{\mathrm{n}}=$ número de plântulas normais germinadas a cada dia; $\mathrm{N}_{1}, \mathrm{~N}_{2}, \ldots \mathrm{N}_{\mathrm{n}}=$ número de dias decorridos da semeadura da primeira até a última contagem.

Comprimento de plântulas - no final do teste de emergência, todas as plântulas normais de cada repetição foram medidas com o auxílio de uma 
régua graduada em centímetros, sendo os resultados expressos em cm/plântula.

Massa seca de plântulas - as mesmas plântulas da avaliação anterior foram acondicionadas em sacos de papel e levados a estufa regulada a $65^{\circ} \mathrm{C}$ até obtenção de peso constante (48 horas) e, decorrido esse período, pesadas em balança analítica com precisão de $0,001 \mathrm{~g}$, sendo os resultados expressos em g/plântula.

Análise estatística e delineamento experimental - os tratamentos foram distribuídos em delineamento experimental inteiramente ao acaso, em quatro repetições de 25 sementes, com fatorial 3 × 2 x 7 (três embalagens, dois ambientes e 7 períodos de armazenamento). Os dados obtidos foram submetidos à análise de variância e de regressão polinomial.

\section{Resultados e Discussão}

Pelos dados referentes ao teor de água das sementes de Amburana cearensis (Figura 1 A e B), observou-se valor inicial em torno de 7,42\%, o qual está de acordo com Figliolia (1988), que classificou as sementes do gênero Amburana como ortodoxas, as quais deveriam ser armazenadas com teor de água em torno de $8 \%$. O teor de água das sementes armazenadas em ambiente de laboratório oscilaram entre 6,25 e $15,89 \%$, enquanto naquelas armazenadas em geladeira, os valores oscilaram entre 6,31 e $9,52 \%$.

Os teores de água mais elevados, em torno de $15,89 \%$, foramverificadosnas sementes armazenadas em sacos de pano no ambiente de laboratório ( \pm $25^{\circ} \mathrm{C}$ ), indicando que estas embalagens permitiram trocas de umidade com o meio, permitindo alterações em seu teor de água durante o período de armazenamento (Figura 1A). Os menores teores de água foram obtidos na embalagem de papel alumínio em geladeira (Figura 1B).
Relacionando-se a umidade relativa nos dois ambientes de armazenamento, verificou-se que no laboratório a umidade relativa variou de 70 a 74,8\%, enquanto na geladeira ficou em torno de $38 \%$. O conhecimento do teor de água das sementes é essencial para se determinar as condições adequadas para o armazenamento, que dependem da umidade relativa, a qual é influenciada pela temperatura do ambiente e pelo tipo de embalagem (WARHM, 1996).

Nas condições de armazenamento estudadas houve redução de percentagem de emergência das plântulas de A. cearensis (Figura 2). Constatou-se que nas sementes armazenadas em embalagens de papel alumínio, no ambiente de laboratório (Figura 2A), houve um declínio menos acentuado no vigor do que naquelas que estavam acondicionadas em embalagens de saco de pano e papel Kraft. Provavelmente esta redução na emergência de plântulas está relacionada às oscilações no teor de água que foi suficiente para promover maiores taxas respiratórias, ocasionando aumento no consumo de reservas das sementes durante a respiração e acelerando a velocidade de deterioração.

No ambiente do laboratório (Figura 2A) observou-se que apenas a embalagem de papel alumínio proporcionou a conservação da viabilidade das sementes até os 270 dias de armazenamento, com a percentagem de emergência em torno de $68 \%$, enquanto as sementes acondicionadas em saco de pano e de papel Kraft apresentaram 5 e 7\% de emergência, respectivamente. Quando as sementes foram armazenadas em geladeira (Figura 2B) verificou-se que houve uma maior conservação, quando comparadas ao ambiente de laboratório, mas isso apenas para as embalagens de saco de pano e de papel Kraft, com emergência de 33 e 30\%, respectivamente. 


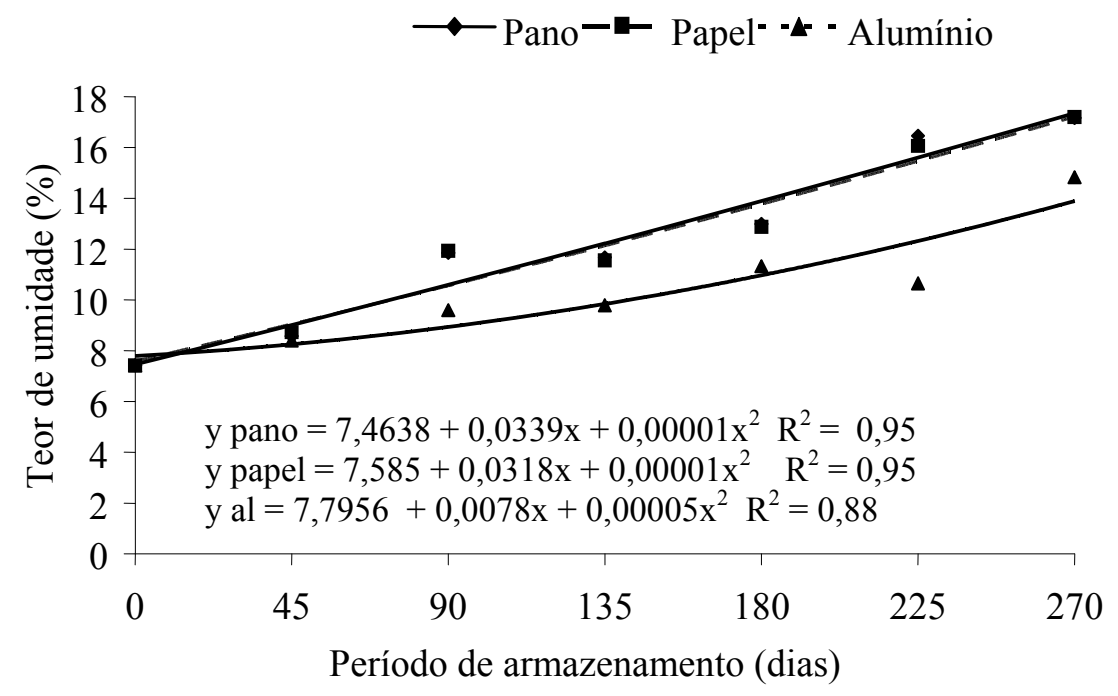

A

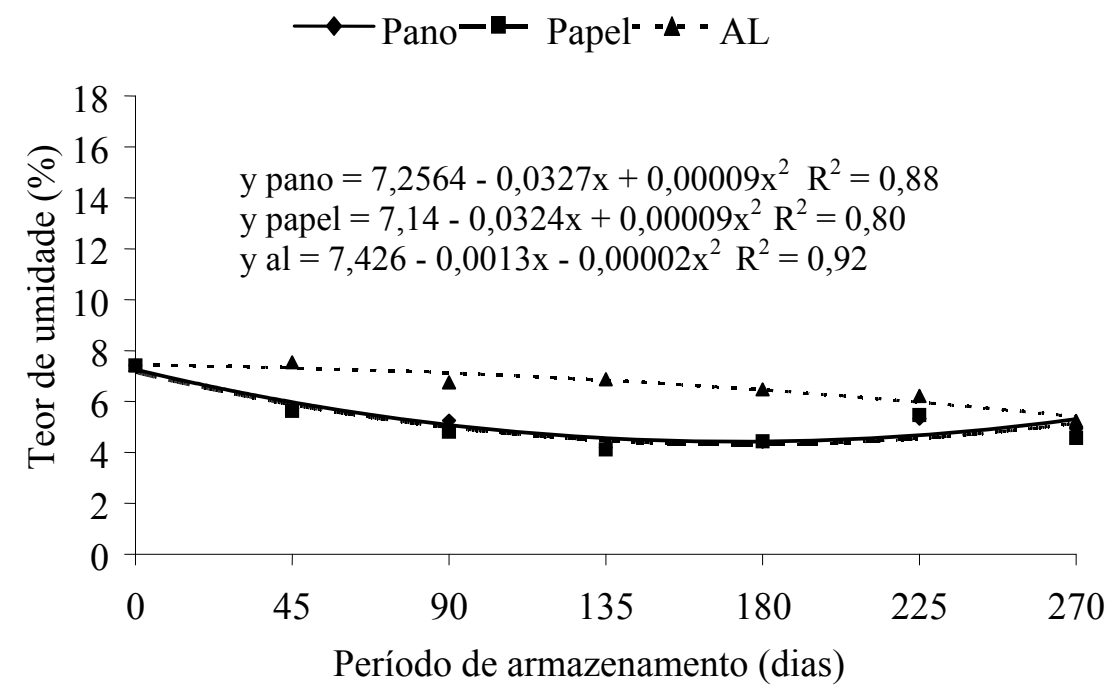

B

Figura 1. Teor de água de sementes de Amburana cearensis (Allemão) A.C. Smith, armazenadas em ambiente de laboratório (A) e em geladeira (B), durante 270 dias. 


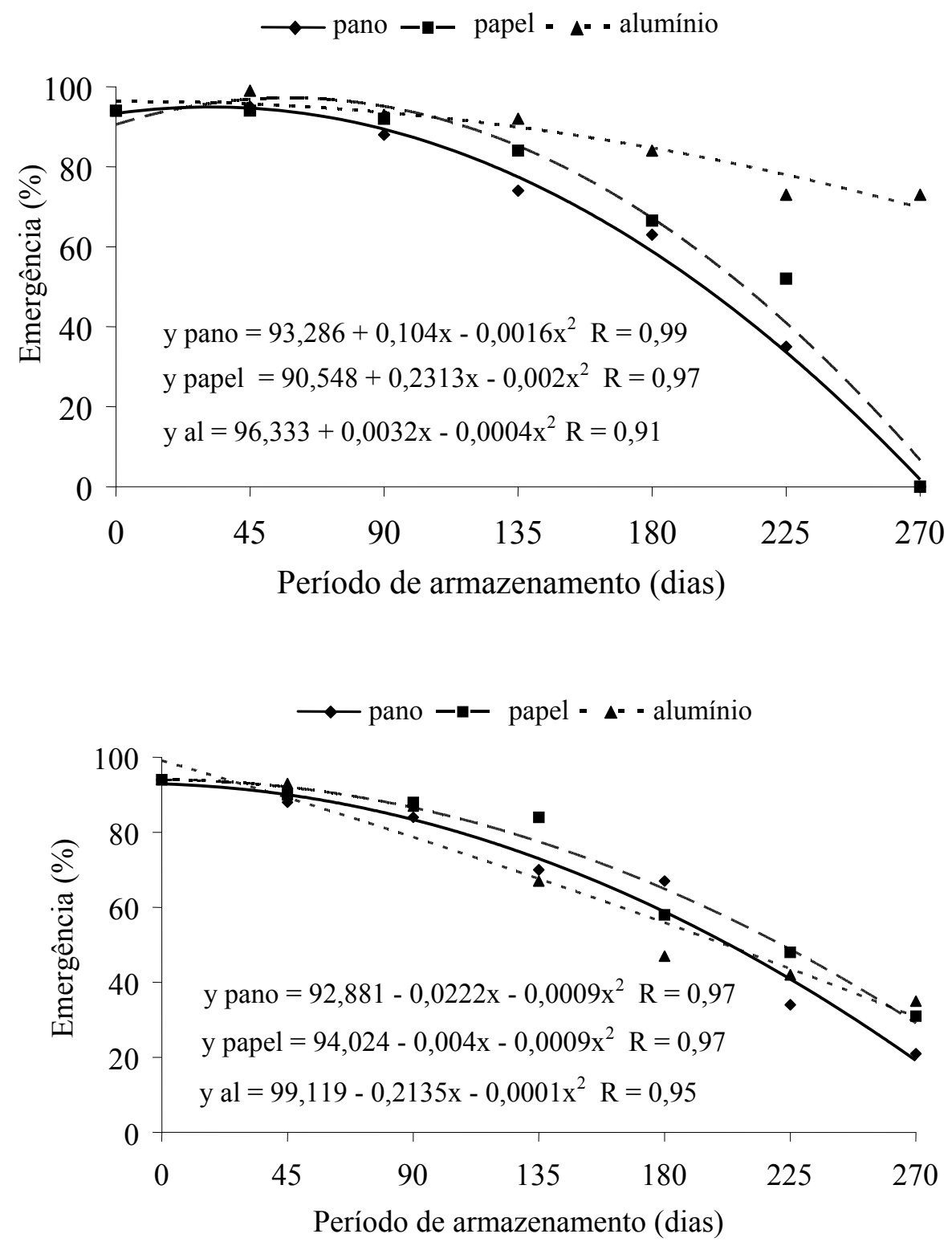

B

Figura 2. Emergência de plântulas de Amburana cearensis (Allemão) A.C. Smith, oriundas de sementes armazenadas em ambiente de laboratório (A) e em geladeira (B), durante 270 dias.

Estes resultados de emergência de plântulas podem se correlacionar com os dados obtidos no teor de água, nos quais se verificou que os menores teores foram observados no ambiente de geladeira. Para as sementes ortodoxas, o teor de água é um dos fatores mais importantes para a manutenção da viabilidade ao longo do tempo, pois a redução no teor de água das sementes causa diminuição da sua atividade metabólica, o que prolonga a sua viabilidade (FOWLER, 2000).
A condição de armazenamento mais adequada para a conservação de sementes de Psidium guineense Swartz, com as menores perdas de viabilidade, foi o ambiente de laboratório, utilizando tanto a embalagem saco de papel Kraft como o vidro (CISNEIROS et al., 2003). O ambiente de laboratório, sem controle de temperatura e umidade relativa do ar não foi eficiente para manutenção da viabilidade das sementes de Acacia polyphylla $\mathrm{DC}$, as quais tiveram a sua germinação reduzida a partir 
do quarto mês de armazenamento (ARAÚJO NETO et al., 2005).

Para sementes de Tabebuia serratifolia (Vahl.) Nich. Souza, Bruno e Andrade (2005) não recomendaram a utilização de embalagens de papel. Caldeira e Perez (2005) recomendam o armazenamento de sementes de Myracrodruon urundeuva (Engl.) em ambiente de laboratório $\left(27,7^{\circ} \mathrm{C}\right.$ e UR de $\left.62,8 \%\right)$, por até seis meses em embalagem metálica, entretanto, para períodos de até um ano, a indicação foi à de ambiente com controle de temperatura e umidade relativa (câmara com temperatura de $15,1{ }^{\circ} \mathrm{C}$ e UR de $74,7 \%$ ) independente do tipo de embalagem.

Os maiores índices de velocidade de emergência de plântulas de $A$. cearensis (Figura 3A) foram detectados nas sementes provenientes do ambiente de laboratório, atingindo valores máximos $(1,67)$ aos 5 dias de armazenamento para as sementes acondicionadas em saco de pano; aos 43 dias para as sementes acondicionadas em papel $\operatorname{Kraft}(1,63)$ e aos 12 dias para as sementes acondicionadas em embalagem de papel alumínio $(1,64)$. Após estes períodos houve redução no vigor das sementes, avaliado pela da velocidade de emergência. Nessa condição de armazenamento pode-se constatar que a embalagem de papel alumínio foi responsável pela manutenção do vigor aos 270 dias de armazenamento. A embalagem de papel alumínio funcionou como uma barreira para as trocas de umidade entre as sementes e o ambiente o que, conseqüentemente, diminuiu a velocidade do processo de deterioração.

Em condições de armazenamento no ambiente de geladeira (Figura 3B) houve redução linear no vigor das sementes em ambas as embalagens, avaliado pelo índice de velocidade de emergência. Resultados semelhantes foram obtidos com sementes de Peltophorum dubium L. acondicionadas em embalagem de vidro e mantidas em ambiente de laboratório (PEREZ; FANTI; CASALI, 1999) e com sementes de Tabebuia serratifolia (Vahl.) Nich., quando acondicionadas em embalagens de papel
Kraft e armazenadas em ambiente de laboratório e em geladeira (SOUZA; BRUNO; ANDRADE, 2005).

As plântulas oriundas das sementes mantidas em ambiente de laboratório emergiram mais rapidamente do que aquelas armazenadas na geladeira. Isto, provavelmente, porque no armazenamento em ambiente de laboratório, o processo de deterioração das sementes ocorreu de forma lenta e gradual, não ocasionando queda brusca na velocidade de emergência das sementes.

Com relação aos resultados obtidos para o vigor baseado no desempenho das plântulas (Figura 4), detectaram-se os maiores comprimentos naquelas originadas de sementes acondicionadas em embalagens de papel alumínio e armazenadas em ambiente de laboratório, pois, apesar de ter ocorrido decréscimo linear no comprimento das plântulas nestas condições, obteve-se uma média de $17,98 \mathrm{~cm}$ aos 270 dias de armazenamento (Figura 4A).

Ainda na Figura $4^{\text {a }}$, observou-se que as embalagens de saco de pano e papel Kraft, no ambiente de laboratório não foram eficazes na conservação do vigor das sementes de $A$. cearensis, uma vez que o comprimento inicial das plântulas foi de $21 \mathrm{~cm}$ quando acondicionadas em saco de pano e de $19 \mathrm{~cm}$ em papel Kraft, decrescendo para valores de 3,5 e 1,1 cm, respectivamente, aos 270 dias após o armazenamento.

O comprimento da raiz primária e da parte aérea de plântulas de Parkia pendula Benth. ex. Walp. oriundas de sementes acondicionadas em embalagens de alumínio, plástico e papel, e armazenadas em câmara refrigerada e ambiente natural foi reduzido a partir do terceiro mês de armazenamento(ROSSETO, 2006). Em sementes de Tabebuia serratifolia (Vahl.) Nich., o comprimento da parte aérea foi eficiente em detectar diferenças entre as embalagens utilizadas, uma vez que houve superioridade das embalagens de polietileno (SOUZA; BRUNO; ANDRADE, 2005), enquanto sementes de Moringa oleifera Lam. armazenadas em 
ambiente de laboratório originaram plântulas mais vigorosas (BEZERRA; MOMENTÉ; MEDEIROS FILHO, 2004).

Quando as sementes de A. cearensis foram armazenadas em ambiente de geladeira (Figura 4B), o comprimento das plântulas decresceu linearmente ao longo dos períodos de armazenamento, independente da embalagem avaliada, chegando a uma média de $13 \mathrm{~cm}$ após 270 dias. Mais uma vez a embalagem de papel alumínio apresentou resultados mais satisfatórios que as demais embalagens, mantendo as sementes mais vigorosas que, consequentemente, originaram plântulas com maior taxa de crescimento, possivelmente pelo maior controle das trocas gasosas, que reduziu a deterioração das mesmas. Em razão disso pode haver uma maior capacidade de translocação de suas reservas e maior assimilação destas pelo eixo embrionário.
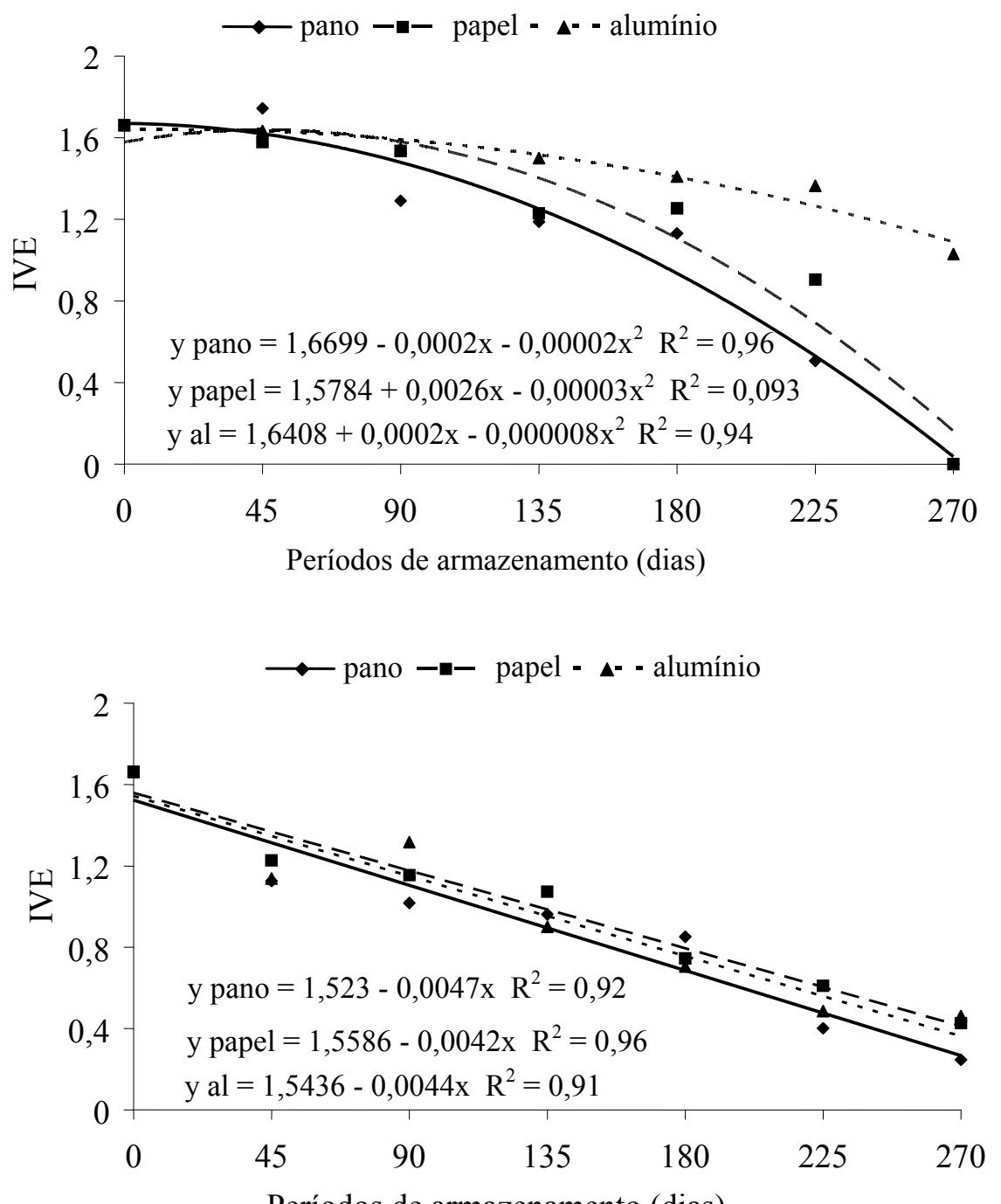

A

Períodos de armazenamento (dias)

B

Figura 3. Índice de velocidade de emergência de plântulas de Amburana cearensis (Allemão) A.C. Smith, oriundas de sementes armazenadas em ambiente de laboratório (A) e em geladeira (B), durante 270 dias. 


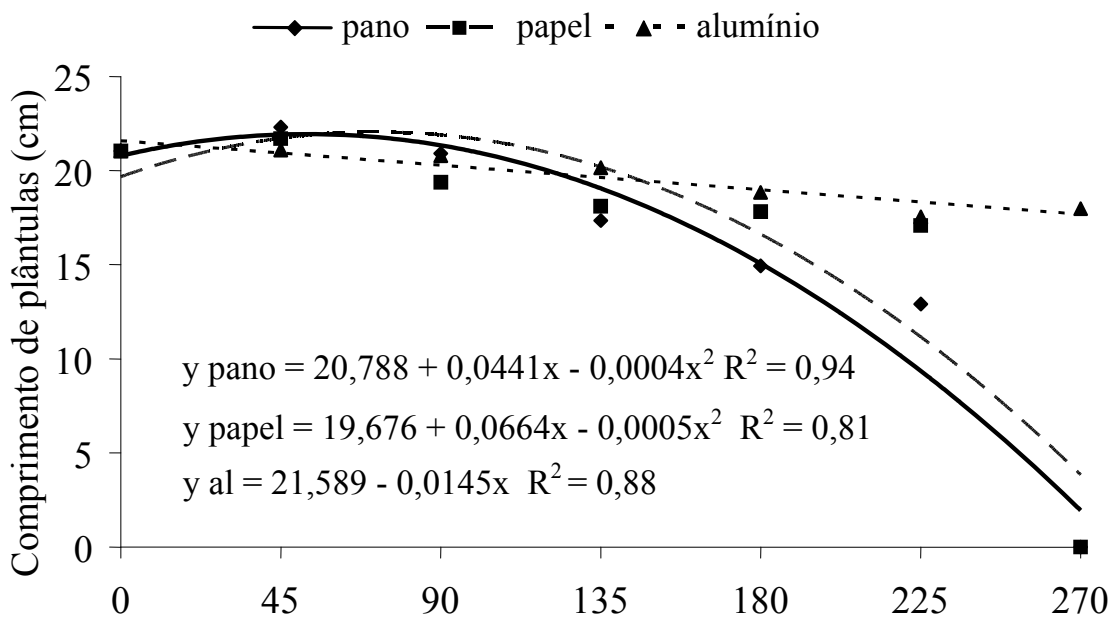

Período de armazenamento (dias)

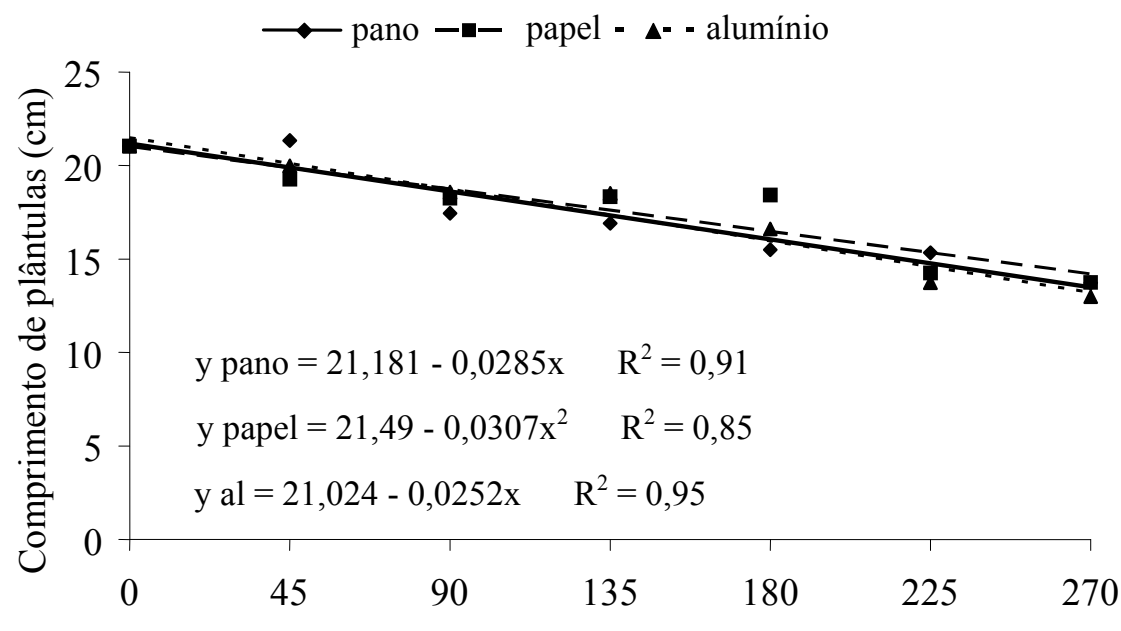

Períodos de armazenamento (dias)

B

Figura 4. Comprimento de plântulas de Amburana cearensis (Allemão) A.C. Smith, oriundas de sementes armazenadas em ambiente de laboratório (A) e em geladeira (B), durante 270 dias.

Quanto à massa seca de plântulas originadas de sementes armazenadas em diferentes embalagens e ambientes (Figura 5), no início do armazenamento não houve diferença na quantidade do conteúdo de massa seca das plântulas $(0,18 \mathrm{~g})$ oriundas de sementes acondicionadas nas embalagens de papel e pano e armazenadas em ambiente de laboratório.
Entretanto, apenas a embalagem de papel alumínio foi eficaz na conservação do vigor das sementes neste ambiente, com cerca de $0,08 \mathrm{~g}$ de massa seca aos 270 dias de armazenamento, enquanto nas embalagens de saco de pano e de papel Kraft o conteúdo de massa seca foi próximo a zero, no mesmo período de armazenamento (Figura 5A). 


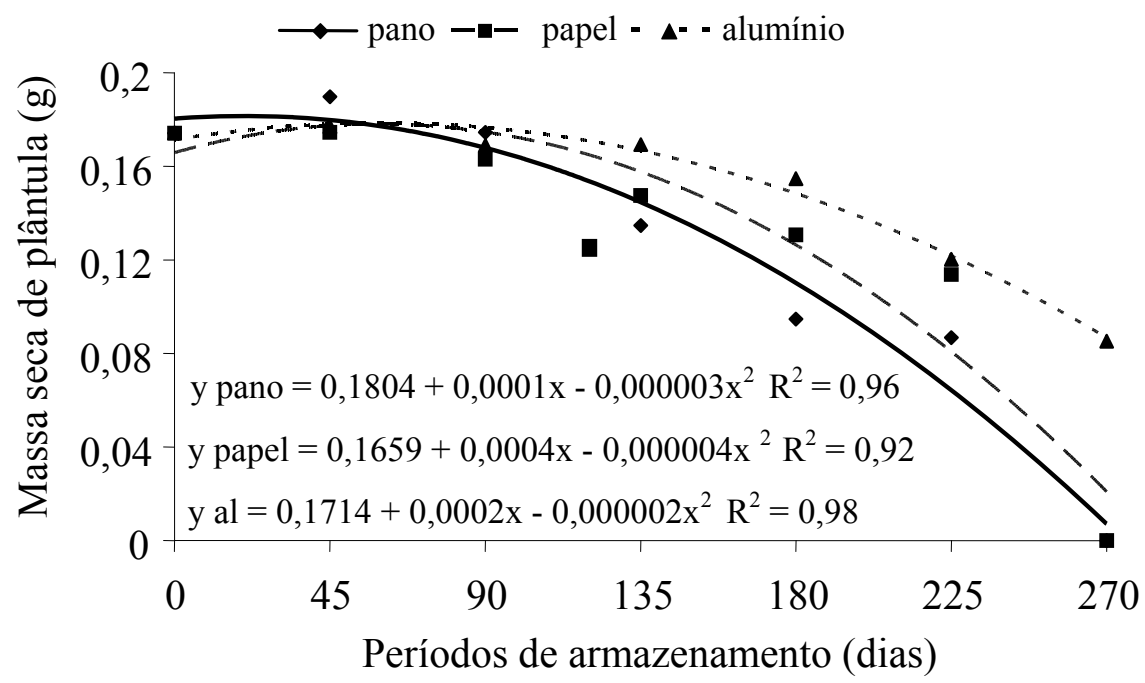

A

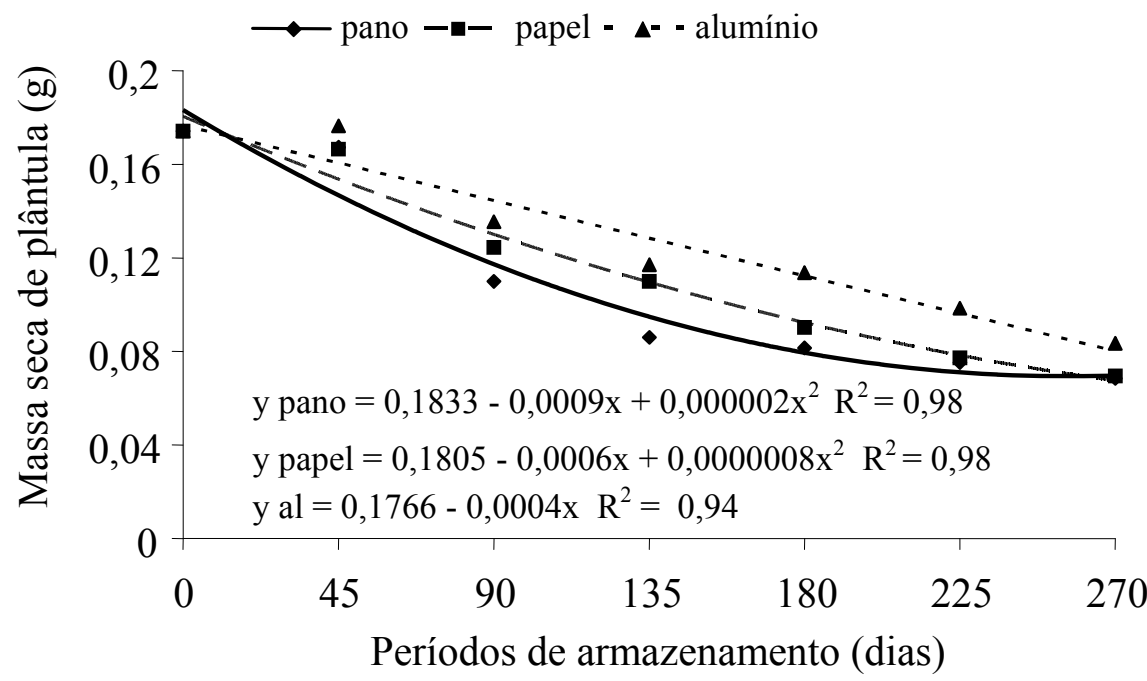

B

Figura 5. Massa seca de plântulas de Amburana cearensis (Allemão) A.C. Smith, oriundas de sementes armazenadas em ambiente de laboratório (A) e em geladeira (B), durante 270 dias.

Quanto ao ambiente geladeira (Figura 5B), observou-se que os valores do conteúdo de massa seca das plântulas provenientes de sementes das embalagens saco e de papel Kraft não diferiram estatisticamente entre si no início do armazenamento, como ocorreu no ambiente de laboratório. Pode-se constatar, no entanto, que no ambiente de geladeira houve uma rápida redução no conteúdo de massa seca das plântulas, com valores próximos de zero ao final do armazenamento. Quando as sementes foram armazenadas na embalagem de papel alumínio houve redução linear do vigor, contudo, constatou-se, mais uma vez, que esta embalagem permite uma menor redução no vigor quando comparada às demais.

Os resultados são semelhantes aos obtidos por Souza, Bruno e Andrade (2005) com sementes de Tabebuia serratifolia (Vahl.) Nich., em que as sementes acondicionadas nas embalagens de papel 
Kraft e polietileno e armazenadas no ambiente de laboratório perderam o vigor ao longo do armazenamento. De forma diferente, Rosseto (2006) observou que ocorreu decréscimo significativo na massa seca das plântulas originadas de sementes acondicionadas em saco de papel e armazenadas na câmara refrigerada.

\section{Conclusão}

A emergência e o vigor das sementes de Amburana cearensis (Allemão) A.C. Smith (cumaru) são conservados, com eficiência, nas embalagens e ambientes por 90 dias e na embalagem de aluminio e ambiente de laboratório por 180 dias.

\section{Referências}

ALIZAGA, R. L.; MELO, V. D. C.; SANTOS, D. S. B.; IRIGON, D. L. Avaliação de testes de vigor em sementes de feijão e suas relações com a emergência em campo. Revista Brasileira de Sementes, Brasília, v. 12, n. 2, p. 44-58, 1990.

ARAÚJO NETO, J. C.; AGUIAR, I. B.; FERREIRA, V. M.; RODRIGUES, T. J. D. Armazenamento e requerimento fotoblástico de sementes de Acacia polyphylla DC. Revista Brasileira de Sementes, Pelotas, v. 27, n. 1, p. 115-124, 2005.

AZEVEDO, M. R. Q. A.; GOUVEIA, J. P. G.; TROVÃO, D. M. M.; QUEIROGA, V. P. Influência das embalagens e condições de armazenamento no vigor de sementes de gergelim. Revista Brasileira de Engenharia Agrícola e Ambiental, Campina Grande, v. 7, n. 3, p. 519-524, 2003.

BARBEDO, C. J.; BILIA, D. A. C.; FIGUEIREDO, R. R. C. L. Tolerância à dessecação e armazenamento de sementes de Caesalpinia echinata Lam. (pau-brasil), espécie da Mata Atlântica. Revista Brasileira de Botânica, São Paulo, v. 25, n. 4, p. 431-439, 2002.

BEZERRA, A. M. E.; MOMENTÉ, V. G.; MEDEIROS FILHO, S. Germinação de sementes e desenvolvimento de plântulas de moringa (Moringa oleifera Lam.) em função do peso de sementes e do tipo de substrato. Horticultura Brasileira, Brasília, v. 22, n. 2, p. 295-299, 2004.

BRASIL. Ministério da Agricultura e Reforma Agrária. Regras para análise de sementes. Brasília: SNDA/ DNDV/CLAV, 1992. 365 p.
CALDEIRA, S. F.; PEREZ, S. C. J. G. A. Viabilidade de sementes armazenadas de aroeira, Myracrodruon urundeuva (Engl.) Fr.All. Informativo ABRATES, Pelotas, v. 15, p. 305-305, 2005.

CARNEIRO, J. G. A.; AGUIAR, I. B. Armazenamento de sementes. In: AGUIAR, I. B.; PIÑA-RODRIGUES, F. C. M.; FIGLIOLIA, M. B. (Ed.). Sementes Florestais Tropicais, Brasília: ABRATES, 1993, p. 333-350.

CARVALHO, N. M.; NAKAGAWA, J. Sementes: ciência, tecnologia e produção. 4. ed. Jaboticabal: FUNEP, 2000. $588 \mathrm{p}$.

CISNEIROS, R. A.; MATOS, V. P.; LEMOS, M. A.; REIS, O. V.; QUEIROZ, R. M. Qualidade fisiológica de sementes de araçazeiro durante o armazenamento. Revista Brasileira de Engenharia Agrícola e Ambiental, Campina Grande, v. 7, n. 3, p. 513-518, 2003.

CORVELLO, W. B. V.; VILLELA, F. A.; NEDEL, J. L.; PESKE, S. T. Época de colheita e armazenamento de sementes de cedro (Cedrela fissilis Vell.). Revista Brasileira de Sementes, Brasília, v. 21, n. 2, p. 28-34, 1999.

DELOUCHE, J. C.; MATTHES, R. K.; DOUGHERTY, G. M.; BOYD, A. H. Storage of seeds in tropical and subtropical regions. Seed Science and Technology, Zurich, v. 21, n. 2, p. 671-700, 1973.

FIGLIOLIA, M. B. Conservação de sementes de essências florestais. São Paulo: Instituto Florestal, 1988. 18p. (Boletim Técnico, 42).

FOWLER, J. A. P. Superação de dormência e armazenamento de sementes de espécies florestais. In: GALVÃO, A. P. M. (Org.) Reflorestamento de propriedades rurais para fins produtivos e ambientais: um guia para ações municipais e regionais. Brasília: Embrapa Comunicação para Transferência de Tecnologia; Colombo: Embrapa Florestas, 2000. p. 77-99.

IBAMA. Instituto Brasileiro de Meio Ambiente e dos Recursos Naturais Renováveis. Lista oficial de espécies da flora brasileira ameaçada de extinção. Portaria n.37-N de 3 de abril de 1992. Disponível em: <http:// www.ibama.gov.br>. Acesso em: 12 dez. 2008.

KAGEYAMA, P. Y.; SANCHEZ, S. P. A.; FERRAZ, E. M.; SOUZA, L. M. C. Armazenamento de sementes de três espécies nativas (Tabebuia heptaphylla, Erytrhina verna e Chorisia speciosa). Revista do Instituto Florestal, v. 4, n. 2, p.435-439, 1992.

LORENZI, H. Árvores brasileiras: manual de identificação e cultivo de plantas arbóreas nativas do Brasil. 2. ed. Nova Odessa: Plantarum. 2002. 368 p. 
MAGUIRE, J. D. Speed of germination aid in selection and evaluation for seeding emergence and vigor. Crop Science, Madison, v. 2, n. 2, p. 76-177, 1962.

PEREZ, S. C. J. G. A.; FANTI, S. C.; CASALI, C. A. Influência do armazenamento, substrato, envelhecimento precoce e profundidade de semeadura na germinação de canafístula. Bragantia, Campinas, v. 58, n. 1, p. 57-68, 1999.

ROSSETO, J. Morfologia, germinação, armazenamento e sanidade de sementes de Parkia pendula (Willd.) Benth. ex Walp. - Fabaceae. 2006. Dissertação (Mestrado em Agricultura Tropical) - Departamento de Fitotecnia e Fitossanidade, Universidade Federal de Mato Grosso. Faculdade de Agronomia e Medicina Veterinária, Cuiabá.

SCALON, S. P. Q.; MUSSURY, R. M.; SCALON FILHO, H.; FRANCELINO, C. F. S.; FLORENCIO, D. K. S. Armazenamento e tratamentos pré-germinativos em sementes de jacarandá (Jacaranda cuspidifolia Mart.). Revista Árvore, Viçosa, v. 30, n. 2, p. 179-185, 2006.

SILVA, A.; FIGLIOLIA, M. B.; AGUIAR, I. B.; PERECIN, D. Liofilização e armazenamento de sementes de ipê-rosa (Tabebuia heterophylla (A.P. Candolle) Britton) - Bignoniaceae. Revista Brasileira de Sementes, Brasília, v. 23, n. 1, p. 252-259, 2001.

SOUZA, V. C.; BRUNO, R. L. A. ANDRADE L. A. Vigor de sementes armazenadas de ipê-amarelo Tabebuia serratifolia (Vahl.) Nich. Revista Árvore, Viçosa, v. 29, n. 6, p.833-841, 2005.

VIEIRA, C. V.; ALVARENGA, A. A.; CASTRO, E. M.; NERY, F. C.; SANTOS, M. O. Germinação e armazenamento de sementes de camboatã (Cupania vernalis Cambess.) Sapindaceae. Ciência e Agrotecnologia, Lavras, v. 32, n. 2, p. 444-449, 2008.

VILLELA, F. A.; PEREZ, W. B. Tecnologia de sementescoleta, beneficiamento e armazenamento. In: FERREIRA, A. G. E BORGHETTI, F. (Coord.). Germinação - do básico ao aplicado. Porto Alegre: Artmed, 2004. p. 265280.

WARHM, E. J. A. Comparison of packing materials for seed with particular reference to humid environments. Seed Science and Technology, Zürich, v. 14, n. 1, p. 191211, 1996. 